OPEN ACCESS

Edited by:

Yujing $L i$,

Emory University, United States

Reviewed by: Kaushlendra Tripathi, University of Alabama at Birmingham,

United States

Jai Prakash,

University of Twente, Netherlands

*Correspondence:

Helen Ka Wai Law

hthelen@polyu.edu.hk

Specialty section: This article was submitted to

$R N A$,

a section of the journal

Frontiers in Genetics

Received: 02 October 2018

Accepted: 31 December 2018

Published: 14 January 2019

Citation:

Islam Khan MZ, Tam SY and

Law HKW (2019)

Autophagy-Modulating Long

Non-coding RNAs (LnCRNAs)

and Their Molecular Events in Cancer.

Front. Genet. 9:750.

doi: 10.3389/fgene.2018.00750

\section{Autophagy-Modulating Long Non-coding RNAs (LncRNAs) and Their Molecular Events in Cancer}

\author{
Md Zahirul Islam Khan, Shing Yau Tam and Helen Ka Wai Law*
}

Department of Health Technology and Informatics, Faculty of Health and Social Sciences, The Hong Kong Polytechnic University, Hong Kong, Hong Kong

Cancer is a global threat of health. Cancer incidence and death is also increasing continuously because of poor understanding of diseases. Although, traditional treatments (surgery, radiotherapy, and chemotherapy) are effective against primary tumors, death rate is increasing because of metastasis development where traditional treatments have failed. Autophagy is a conserved regulatory process of eliminating proteins and damaged organelles. Numerous research revealed that autophagy has dual sword mechanisms including cancer progressions and suppressions. In most of the cases, it maintains homeostasis of cancer microenvironment by providing nutritional supplement under starvation and hypoxic conditions. Over the past few decades, stunning research evidence disclosed significant roles of long non-coding RNAs (IncRNAs) in the regulation of autophagy. LncRNAs are RNA containing more than 200 nucleotides, which have no protein-coding ability but they are found to be expressed in most of the cancers. It is also proved that, autophagy-modulating IncRNAs have significant impacts on pro-survival or pro-death roles in cancers. In this review, we highlighted the recently identified autophagy-modulating IncRNAs, their signaling transduction in cancer and mechanism in cancer. This review will explore newly emerging knowledge of cancer genetics and it may provide novel targets for cancer therapy.

Keywords: autophagy, long non-coding RNAs, cancer, therapy, biomarkers

Abbreviations: ATGs, autophagy-related genes; BANCR, BRAF-activated long non-coding RNA; BDC, bladder cancer; BRC, breast cancer; BT, brain tumor; CASC2, cancer susceptibility candidate gene 2; CRC, colorectal cancer; CTA, LncRNA CTA; DFS, disease-free survival; EMT, epithelial-mesenchymal transition; ENDC, endometrial cancer; GAS5, growth arrestspecific 5; GC, gastric cancer; GMEC, glioma microvascular endothelial cancer; HCC, hepatocellular carcinoma; HMGB1, high-mobility group box 1 protein; HNC, head and neck cancer; HNF 1A-AS1, a natural antisense transcript of HNF 1A; HOTAIR, Hox transcript antisense RNA; HULC, highly up-regulated in liver cancer; LC, lung cancer; LCPAT1, lung cancer progression associated transcript 1; LEUK, leukemia; lncRNAs, long non-coding RNAs; LNM, lymphatic node metastasis; LVC, liver cancer; MALAT1, metastasis-associated lung adenocarcinoma transcript 1; MEG3, maternally expressed gene 3; MM, multiple myeloma; MPM, malignant pleural mesothelioma; ncRNAs, non-coding RNAs; NGS, next-generation sequencing; NSCLC, non-small-cell lung cancer; OS, overall survival; OSTS, osteosarcoma; OVC, ovarian cancer; PCA3, prostate cancer antigen 3; PDA, pancreatic ductal adenocarcinoma; PKM2, pyruvate kinase isozymes 2; PNC, pancreatic cancer; PPTC, papillary thyroid carcinoma; PRKD3, protein kinase D3; PTC, prostate cancer; PTENP1, pseudogene of tumor suppressor gene PTEN; PVT1, plasmacytoma variant translocation 1; ROR, regulator of reprogramming; RTB, retinoblastoma; SB, sleeping beauty; sirt1, silent information regulator 1; STAT3, signal transducer and activator of transcription 3; TNM, tumor node metastasis. 


\section{INTRODUCTION}

Cancer is a global threat of public health because of its high mortality rate. More than 14 million of new cancer cases and $\sim 60 \%$ of death were accounted in 2012 by GLOBOCAN data (Figure 1A). It is also assumed that more than 20 million new cancer cases will be counted in the year 2025 (Ferlay et al., 2015). Cancer death is increasing day by day, 8.8 million death were counted in 2015 where abundant death was reduced in low to moderate income countries (Figure 1B) (GBD 2015 Risk Factors Collaborators, 2016; WHO, 2018). The cancer cases in 10 Asian countries are also estimated to increase from in 6.1 million to 10.7 million in the year 2008 to 2030 respectively. The consecutive death was estimated to raise from 4.1 million to 7.5 million (Sankaranarayanan et al., 2014).

Metastatic tumors are the leading cause of death and pose a great challenge for cancer treatments. Although the molecular basis of carcinogenesis is different in different cancers, the metastasis developmental process is almost similar in all solid tumor cells (Bogenrieder and Herlyn, 2003). The aim of traditional treatments of cancer is either removing or destroying cancerous cells by surgery, radiation therapy, chemotherapy and sometimes personalized treatment. Theoretically, these traditional treatments are very promising but practically none of these are able to cure effectively and efficiently because of poor understating of mechanisms and development of metastasis (Wang Z. et al., 2016).

Autophagy is a highly conserved and critical regulatory process for cells to maintain homeostasis by lysosomal degradation of various proteins and damaged organelles. Dynamic roles of autophagy have been identified in cancers where it participates in cancer progression, prevention, as well as, drug resistance mechanisms (Santana-Codina et al., 2017). There are three types of autophagy: macroautophagy, microautophagy, and chaperone-mediated autophagy. Macroautophagy is sometimes also referred to as autophagy which is the major autophagic pathways and most extensively studied compared to microautophagy and chaperone-mediated autophagy. In macroautophagy, phagophore is initially formed and matured to autophagosome. Subsequently, autophagosome fused with a lysosome to degrade the internal materials in autolysosome (Figure 2) (Mizushima and Komatsu, 2011). Although autophagy may suppress tumors (Kung et al., 2011) in most cases, the induction of autophagy promotes tumorigenesis by providing survival capability of tumor under microenvironmental stress (Kung et al., 2011; Avalos et al., 2014; White, 2015). Autophagy promotes cancer by inhibiting tumor suppressor protein p53 and controlling the metabolism of cells (Amaravadi et al., 2016). Cellular metabolism and homeostasis are encoded by more than 30 ATGs, their translational products and transduction of signals (Figure 2) (Kim and Lee, 2014; Cicchini et al., 2015; Ktistakis and Tooze, 2016). Tumorigenesis of both benign and malignant tumors are controlled by either single or group of ATG genes (Blessing et al., 2017; Mowers et al., 2017). Thus, in most of the cancers, autophagy is key therapeutic choices in clinical trials (Mowers et al., 2016).
There is increasing evidence that a large number of ncRNAs are actively transcribed from the human genome, controlling diverse cellular metabolic process in growth and development of cancers through regulating various gene expressions (Lin and $\mathrm{He}, 2017)$. Most diverse ncRNAs, specifically lncRNAs, are largely involved in cancer initiation, maturation, metastasis and resistance against chemotherapy (Lin and $\mathrm{He}, 2017$; Hu et al., 2018). LncRNAs are $>200$ nucleotides in length and are mostly transcribed by RNA polymerase II. According to GENCODE (version 18), 13,562 lncRNAs have been identified (Huang X. et al., 2017). LncRNAs have independent expressions in different tissues and different cancers and are responsible for various cancers including BRC, CRC, GC, glioma, HCC, leukemia, LVC, LC, OVC, PTC, and retinoblastoma (He et al., 2016; Huang J. et al., 2017; Huang X. et al., 2017; Li et al., 2017b,d,e; Luo et al., 2017; Ma et al., 2017d; Jiang et al., 2018; Li H. et al., 2018).

Over the past decades, advance research evidence has shown that lncRNAs regulate most of the cancers by means of controlling the autophagy process and modulating the transcriptional and post-transcriptional ATGs (Mowers et al., 2017; Zhang J. et al., 2017). In this review, we aim to provide an overview of recently identified autophagy-modulating lncRNAs autophagy in cancers, their mechanisms and future directions on therapeutic intervention.

The field of targeted therapy is rapidly developing with advanced genetic study and their successful applications. Previously considered junk molecules such as lncRNAs are now extensively studied to be established as novel diagnostic biomarkers and therapeutic targets. The biological and physiological roles of autophagy-modulating lncRNAs in carcinogenesis are being unveiled recently. The expression of lncRNAs greatly impacts on the extent of autophagy at different carcinogenic stages, mostly in advanced metastatic stages. A number of research articles suggested that lncRNAs induce or suppress autophagy through ATGs and their signaling pathways (Table 1). The complex process of autophagy modulation by expressions of lncRNAs may suppress or promote carcinogenesis under diverse physiological conditions (Figure 3). Here we described below the recently characterized lncRNAs and their mechanisms through inducing or inhibiting autophagy in different cancers. We also summarized some autophagymodulating lncRNA which worth further investigation in the field of cancer.

\section{AUTOPHAGY-INDUCING LncRNAs IN CANCER}

Majority of the autophagy-modulating lncRNAs have a positive relationship with the induction of autophagy. Hence, increase expression of these IncRNA in tumor induced autophagy and decrease expression of these lncRNA suppressed autophagy. Some examples are listed as follow.

\section{HOX Transcript Antisense RNA}

HOX transcript antisense RNA contains 2158 nucleotides and was discovered by Rinn et al. (2007). It is located on intergenic 
A

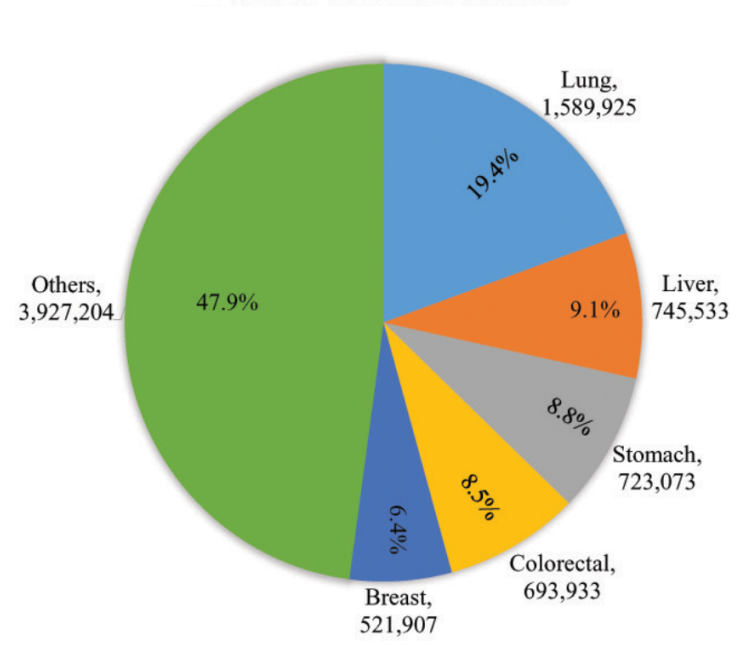

B

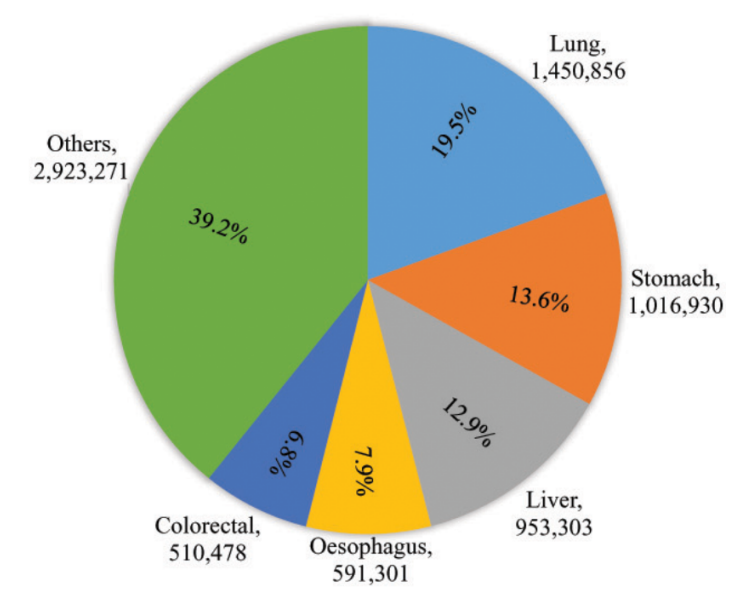

FIGURE 1 | Global cancer impact in (A) 2012 and (B) 2015. In 2012, the death toll 8.2 million from 14 million new cases. It raised gradually to 8.8 million in 2015. The growth of cancer death was more than $7 \%$ from 2012 to 2015 . The most common cancers were Lung cancer, liver cancer, stomach cancer, colorectal cancer, esophageal cancer, and breast cancer was a major threat of women cancer death worldwide. These figures were based on data published by WHO and GLOBOCAN (Ferlay et al., 2015; GBD 2015 Risk Factors Collaborators, 2016; WHO, 2018).

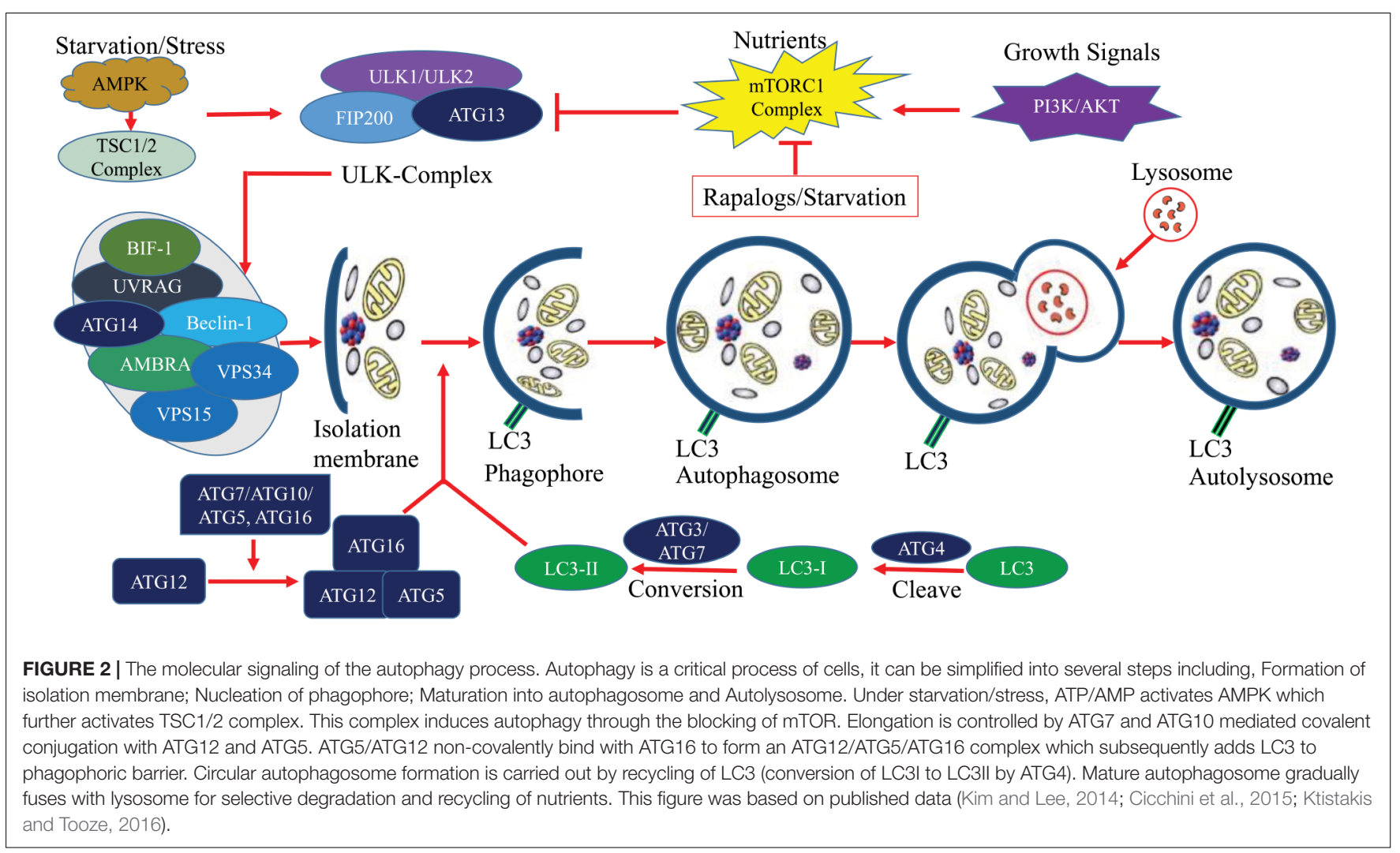

space of HOXC11 and HOXC12 in chromosome 12q13.13 (Rinn et al., 2007). Abnormal expression of HOTAIR has been noticed for most of the cancers including, BT, BRC, CRC, GC, LVC, NSCLC, OVC, and PNC (Loewen et al., 2014; Zhou et al., 2014; Miao et al., 2016; Gerardo et al., 2017). Several research groups have reported HOTAIR association in different cancers evolutionary processes including, EMT, TNM, prognosis, drug resistance, metastasis, DFS, OS, and tumor development (Loewen et al., 2014; Zhou et al., 2014). Recently, a growing number of studies have revealed HOTAIR contexts in the 
TABLE 1 | List of autophagy-modulating IncRNAs and their roles in various cancer.

\begin{tabular}{|c|c|c|c|c|c|}
\hline LncRNAs & $\begin{array}{l}\text { Expression in } \\
\text { cancer }\end{array}$ & $\begin{array}{l}\text { Autophagy } \\
\text { modulation }\end{array}$ & Functions & Sources & Reference \\
\hline AC023115.3 & Up-regulated & Inhibit autophagy & $\begin{array}{l}\text { Increase cisplatin -mediated apoptosis } \\
\text { in glioma }\end{array}$ & Glioma cell lines & Ma et al., 2017b \\
\hline BANCR & Up-regulated & Induce autophagy & $\begin{array}{l}\text { Promote PPTC proliferation, growth } \\
\text { and reduce cell population at G1 phase. }\end{array}$ & Cell line and tumor samples & Wang et al., 2014 \\
\hline CASC2 & $\begin{array}{l}\text { Down- } \\
\text { regulated }\end{array}$ & Induce autophagy & $\begin{array}{l}\text { Glioma progression and temozolomide } \\
\text { resistance through controlling mTOR }\end{array}$ & $\begin{array}{l}\text { Glioma cells, tissues and } \\
\text { peritumoral brain edema } \\
\text { tissues }\end{array}$ & Jiang et al., 2018 \\
\hline CTA & $\begin{array}{l}\text { Down- } \\
\text { regulated }\end{array}$ & Induce autophagy & $\begin{array}{l}\text { Promote TNM, larger tumor depth and } \\
\text { reduced chemosensitivity in OSTS }\end{array}$ & $\begin{array}{l}\text { OSTS cells and tissues (without } \\
\text { pre-operative therapy) }\end{array}$ & Wang Z. et al., 2017 \\
\hline GAS5 & $\begin{array}{l}\text { Down- } \\
\text { regulated }\end{array}$ & $\begin{array}{l}\text { Induce } \\
\text { autophagy/inhibit } \\
\text { autophagy }\end{array}$ & $\begin{array}{l}\text { Progression of NSCLC and cisplatin } \\
\text { resistance; progression of glioma and } \\
\text { cisplatin resistance by inducing } \\
\text { autophagy }\end{array}$ & $\begin{array}{l}\text { NSCLC cell lines and stage III } \\
\text { tumor tissues; Glioma cell lines }\end{array}$ & $\begin{array}{l}\text { Zhang et al., 2016; Huo } \\
\text { and Chen, } 2018\end{array}$ \\
\hline $\mathrm{H} 19$ & Up-regulated & Induce autophagy & $\begin{array}{l}\text { Promote PPTC pathogenesis by } \\
\text { promoting proliferation }\end{array}$ & PPTC cells and tissues & Li M. et al., 2018 \\
\hline HNF1A-AS1 & Up-regulated & Induce autophagy & $\begin{array}{l}\text { Promote TNM, increase growth and } \\
\text { apoptosis in HCC }\end{array}$ & $\begin{array}{l}\text { HCC cells and surgically } \\
\text { resected tissues }\end{array}$ & Liu et al., 2016 \\
\hline HOTAIR & Up-regulated & Induce autophagy & $\begin{array}{l}\text { Cancer progression and drug } \\
\text { resistance in HCC and ENDC }\end{array}$ & $\begin{array}{l}\text { HCC cells and tissues; ENDC } \\
\text { cell lines }\end{array}$ & $\begin{array}{l}\text { Yang et al., 2016; Bao } \\
\text { et al., 2017; Sun et al., } \\
2017\end{array}$ \\
\hline HULC & Up-regulated & $\begin{array}{l}\text { Induce autophagy/ } \\
\text { Inhibit autophagy }\end{array}$ & $\begin{array}{l}\text { Promote GC proliferation, migration, } \\
\text { and invasion, and reduced apoptosis } \\
\text { by inducing autophagy; } \\
\text { chemosensitivity of HCC is promoted } \\
\text { by inhibiting autophagy }\end{array}$ & $\begin{array}{l}\text { GC cells and tissues; HCC cell } \\
\text { lines and tissues }\end{array}$ & $\begin{array}{l}\text { Zhao et al., 2014; Xiong } \\
\text { et al., } 2017\end{array}$ \\
\hline LCPAT1 & Up-regulated & Induce autophagy & $\begin{array}{l}\text { Promote carcinogenesis of } L C \text { and } \\
\text { knockdown gradually reduce in vivo } \\
\text { tumor size }\end{array}$ & $\begin{array}{l}\text { LC cell lines and patients } \\
\text { sample }\end{array}$ & Yu et al., 2018 \\
\hline LncRNA-p21 & Up-regulated & Induce autophagy & $\begin{array}{l}\text { Promote proliferation, motility, reduce } \\
\text { apoptosis and radio-sensitivity in } \\
\text { hepatoma and glioma }\end{array}$ & Glioma cells and urine samples & $\begin{array}{l}\text { Işın et al., 2015; Shen et al., } \\
2017\end{array}$ \\
\hline MALAT1 & Up-regulated & Induce autophagy & $\begin{array}{l}\text { Promote cell proliferation, metastasis, } \\
\text { and autophagy induced drug resistance } \\
\text { in MM, PTC, and GC }\end{array}$ & $\begin{array}{l}\text { MM cell lines; PNC cells and } \\
\text { pancreatic ductal } \\
\text { adenocarcinoma tissues; GC } \\
\text { cell lines }\end{array}$ & $\begin{array}{l}\text { Li L. et al., 2016; Yuan } \\
\text { et al., 2016; Fu et al., 2017; } \\
\text { Gao D. et al., 2017; Huang } \\
\text { J. et al., 2017; YiRen et al., } \\
2017\end{array}$ \\
\hline MEG3 & $\begin{array}{l}\text { Down- } \\
\text { regulated }\end{array}$ & $\begin{array}{l}\text { Induce } \\
\text { autophagy/inhibit } \\
\text { autophagy }\end{array}$ & $\begin{array}{l}\text { Reduced expression promote BDC } \\
\text { proliferation, colony formation, and } \\
\text { progression through inducing } \\
\text { autophagy; while upregulation lead to } \\
\text { OVC proliferation and progression is } \\
\text { raisedvia inhibiting autophagy }\end{array}$ & $\begin{array}{l}\text { BDC cells and tissues; } \\
\text { Epithelial OVC cell and tissues } \\
\text { with different stages }\end{array}$ & $\begin{array}{l}\text { Ying et al., 2013; Xiu et al., } \\
2017\end{array}$ \\
\hline PCA3 & Up-regulated & Inhibit autophagy & $\begin{array}{l}\text { Increase proliferation, migration, and } \\
\text { invasion in PTC }\end{array}$ & PTC cells and tissues & He et al., 2016 \\
\hline POU3F3 & Up-regulated & Inhibit autophagy & $\begin{array}{l}\text { Promote CRC proliferation and } \\
\text { migration }\end{array}$ & CRC cells and tissues & Shan et al., 2016 \\
\hline PTENP1 & $\begin{array}{l}\text { Down- } \\
\text { regulated }\end{array}$ & Inhibit autophagy & $\begin{array}{l}\text { Promote proliferation and migration in } \\
\mathrm{HCC}\end{array}$ & HCC cell lines & Chen et al., 2015 \\
\hline PVT1 & Up-regulated & Induce autophagy & $\begin{array}{l}\text { Promote GMEC proliferation migration } \\
\text { and angiogenesis }\end{array}$ & $\begin{array}{l}\text { Cerebral microvascular } \\
\text { endothelial cell line }\end{array}$ & Ma et al., 2017c \\
\hline ROR & Up-regulated & $\begin{array}{l}\text { Inhibit } \\
\text { autophagy/induce } \\
\text { autophagy }\end{array}$ & $\begin{array}{l}\text { Promote proliferation, invasion, } \\
\text { migration, tamoxifen resistance and } \\
\text { reduced gemcitabine- induced cell } \\
\text { death in BRC; up-regulated in PNC to } \\
\text { reduce chemosensitivity }\end{array}$ & $\begin{array}{l}\text { BRC cells and tissues (without } \\
\text { any therapy); PNC cells and } \\
\text { tissues }\end{array}$ & $\begin{array}{l}\text { Chen Y.M. et al., 2016; Li } \\
\text { C. et al., 2016; Li et al., } \\
2017 f\end{array}$ \\
\hline
\end{tabular}

BDC, bladder cancer; BRC, breast cancer; CRC, colorectal cancer; ENDC, endometrial cancer; GC, gastric cancer; GMEC, glioma microvascular endothelial cancer; HCC, hepatocellular carcinoma; LC, lung cancer; MM, multiple myeloma; NSCLC, non-small cell lung cancer; OSTS, osteosarcoma; OVC, ovarian cancer; PNC, pancreatic cancer; PPTC, papillary thyroid cancer; PTC, prostate cancer; TNM, tumor node metastasis. 


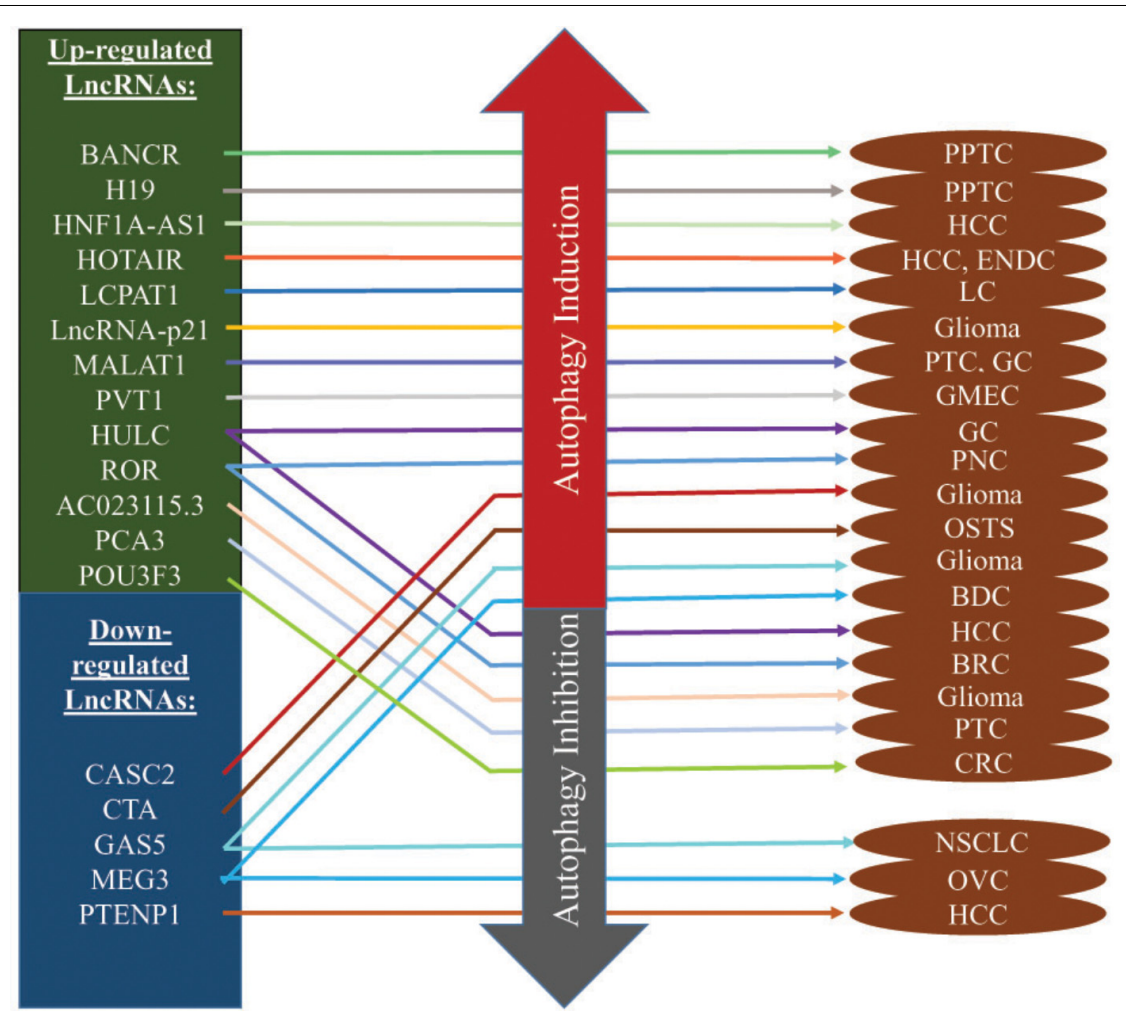

FIGURE 3 | Autophagy-modulating IncRNAs in cancer. Most of the IncRNAs are overexpressed and they induce autophagy to promote/inhibit carcinogenesis. Some of them play key roles in drug resistance while some inhibit autophagy to maintain homeostasis in cancer micro-environments. In the contrary, down-regulated IncRNAs induce/suppress autophagy to promote/inhibit cancer progression.

regulation of autophagy, cancer progression, and drug resistance (Yang et al., 2016; Bao et al., 2017; Sun et al., 2017). Liu's research group proved that, upregulated HOTAIR in HCC cells and tissues induce autophagy by promoting two major ATG3 and ATG7 (Yang et al., 2016). It is also proved that, HOTAIR expression increase along with STAT3 and ATG12 (key of autophagosome formation) through suppressing cancer suppressing micro RNA miR-454-3p in chondrosarcoma (Bao et al., 2017). Sun et al. (2017) revealed that HOTAIR abundancy in ENDC cells significantly induce autophagy which controls the development of chemo-resistance toward cisplatin through the expression of Beclin-1 and P-glycoprotein.

\section{Metastasis-Associated Lung Adenocarcinoma Transcript 1}

Metastasis-associated lung adenocarcinoma transcript 1 is located on chromosome 11q13, containing over $8.7 \mathrm{~kb}$ nucleotides and was first identified in NSCLC since 2003 (Ji et al., 2003). It has been proven that MALAT1 plays significant roles in the development, proliferation, invasion, and metastasis of BDC, BRC, CRC, HCC, LC, NSCLC, and osteosarcoma (OSTS) (Ji et al., 2003; Gutschner et al., 2013; Hou et al., 2017; Li et al., 2017c; Zuo et al., 2017; Xiong et al., 2018). Up-regulated MALAT1 promote proliferation and metastasis of PTC cells and tissues (Li L. et al., 2016) via inducing autophagy. To facilitate the process, MALAT1 interacts with RNA binding protein HuR to activate autophagy via controlling post-transcriptional effects of cytotoxic granule-associated RNA binding protein TIA1 (Li L. et al., 2016). It has also been postulated that, aberrant expression of MALAT1 modulate autophagy in various cancers including glioma, GC, HCC, and RTB by controlling micro RNAs miR216b, miR-101, miR-124, and miR-23b-3p (Yuan et al., 2016; Fu et al., 2017; Huang X. et al., 2017; YiRen et al., 2017). To maintain homeostasis of the cancer micro-environments, up-regulated MALAT1 induce conserved autophagy process directly or indirectly to take part in the progression of chemo-resistance and multi-drug resistance (Yuan et al., 2016; YiRen et al., 2017). More recently, YiRen et al. (2017) revealed that MALAT1 regulate GC progression and autophagy-mediated chemo-resistance via controlling micro RNA miR-23b-3p (YiRen et al., 2017). Gao D. et al. (2017) demonstrated that MALAT1 is highly expressed in $\mathrm{MM}$ along with HMGB1 to promote carcinogenesis by significantly expressing two key autophagy regulatory proteins LC3B and Beclin 1 (The mammalian ortholog of yeast ATG6). Their in vivo investigation suggests that knockdown of MALAT1 would be an effective target of MM growth inhibition by autophagy suppression (Gao D. et al., 2017).

\section{Plasmacytoma Variant Translocation 1}

Plasmacytoma variant translocation 1 was first identified in murine leukemia virus-mediated T lymphomas. It contains 1716 
nucleotides and is located on chromosome 8q24.21 (Zeidler et al., 1994). After its discovery, the roles of PVT1 have been identified in various cancers, including BDC, BRC, LC, MPM, and NSCLC (Cui et al., 2016; Li et al., 2017d; Lu et al., 2017; Zhang X.W. et al., 2017; Zhou et al., 2017; Guo et al., 2018; Li H. et al., 2018). Ma and coworkers proved that PVT1 is significantly upregulate in GMEC and promote Atg7 and Beclin-1 expression. They reported that excessive endothelial cell proliferation and migration is mediated by PTV1/Atg7/Beclin-1 (Ma et al., 2017c). Huang and co-workers revealed that expression of PVT1 directly activates ULK1, an autophagy activating protein, in PDA) cells, patients sample, and in vivo xenograft model. PVT1 promotes pathogenesis by regulating miR-20a-5p (Huang et al., 2018). Thus, PVT1/ULK1/autophagy/miR-20a-5p may lead to being a novel therapeutic target of PDA.

\section{H19}

Maternally expressed non-protein coding transcript H19 is lying on the imprinted region of chromosome $11 \mathrm{p} 15.5$ and it is $2.3 \mathrm{~kb}$ in length (Cui et al., 2002). H19 is transcribed by RNA polymerase II and dysregulation of $\mathrm{H} 19$ is associated with BRC, CRC, GC, Glioblastoma, HCC, HNC, LC and NSCLC (Hu et al., 2016; Matouk et al., 2016; Chen et al., 2017b; Luo et al., 2017). Brannan et al. (1990) first discovered H19 as a riboregulator. To date, numerous evidence has been established for H19's association in various human cancers through distinctive molecular pathways (Chen T. et al., 2016; Chen et al., 2017b). Expression of H19 was found to be increased in both PPTC cells and tissues along with estrogen receptor $\beta$ which may trigger autophagy through regulating ROS and ERK1/2 pathways. Higher expression of H19 promotes PPTC pathogenesis where further investigation may lead to better understanding of PPTC carcinogenesis through H19/autophagy regulation (Li M. et al., 2018).

\section{Others}

Increasing number of autophagy-modulating lncRNAs are being identified but some of them attracted less attention. Wang et al. (2014) described, BANCR activate autophagy and contribute to proliferation and apoptosis of both PPTC cells and tissues. The overexpression of BANCR promote conversion of LC3II/LC3-I, activated autophagy promote cells growth and reduce apoptosis in G1 phase (Wang et al., 2014). LncRNA-p21 is a hypoxia-responsive intergenic non-coding RNA which is highly expressed in hepatoma and glioma (Işın et al., 2015; Shen et al., 2017). Overexpression of lncRNA-p21 is associated with autophagy induction in hepatoma and glioma cells through HIF-1/Akt/mTOR/P70S6K pathways, resulting in excessive proliferation, motility, reduced apoptosis, and reduced radiosensitivity. Therefore, knockdown of lncRNA-p21 is a new target of radiotherapy as its knockdown potentially alter the molecular events and increase radiosensitivity of hypoxic tumor cells (Shen et al., 2017). HNF 1A-AS1 is located on chromosome 12. It is associated with larger tumor size, advanced TNM stage, excessive growth and apoptosis process of HCC cells and tissues through sponging tumor suppressor miR-30b-5p and inducing autophagy (Liu et al., 2016). Yu et al. (2018), recently noticed LCPAT1 lncRNA in LC which is directly regulated with autophagic flux. The overexpression of LCPAT1 and LC3 was found to be in both LC cells and tumor samples which accelerate the autophagic flux formation to promote carcinogenesis. Whereas, knockdown of LCPAT1 can significantly reduce in vivo tumor size by reducing LC3, ATG3, ATG5, ATG7, ATG12, ATG14, and Beclin1expression (Yu et al., 2018). Chen and coworkers shown that PTENP1 is a lncRNA which is downregulated in HCC and SB based hybrid baculovirus vectors mediated insertion of PTENP1 potentially work as targeted anti-tumor agent in HCC cells by reducing proliferation and migration by activating autophagy in PI3K/AKT pathways (Chen et al., 2015).

\section{AUTOPHAGY-INHIBITING LncRNAs IN CANCER}

Some lncRNA has an inverse relationship with autophagy and one example that has been studied extensively is MEG3. MEG3 is an imprinted gene which was first identified in 2000 (Miyoshi et al., 2000). It contains $\sim 1600$ nucleotides and is found in 14q32.3 chromosomal position ( $\mathrm{Ma}$ et al., 2018). Extensive research demonstrated that MEG3 expression is significantly reduced in cancer and it affects the proliferation, migration, and metastasis of most cancers including BRC, CRC, GC, glioma, HCC, LC, NSCLC, and PNC (Gong and Huang, 2017; He et al., 2017; Wang P. et al., 2017; Wei and Wang, 2017; Zhang C.Y. et al., 2017; Ma et al., 2018). Ying et al. (2013) speculated that MEG3 inversely regulate cellular autophagy process via the p53 pathways, and reduced MEG3 induce autophagy to promote BDC proliferation and progression. Down-regulation of MEG3 promote tumorigenesis and progression of epithelial OVC cells proliferation and colony formation through inhibiting autophagy process (Xiu et al., 2017). On the other hand, up-regulation of MEG3 inhibits the expression of autophagy-related proteins LC3, ATG3, and LAMP1 (Xiu et al., 2017). These findings led to the development of MEG3 as a potential biomarker of early diagnosis and treatment of OVC. More recently, Ma et al. (2017a) also proved that MEG3 is association with cisplatin-induced glioma cells death by regulating autophagy.

\section{Others}

Jiang et al. (2018) explored a novel relationship of CASC2 in temozolomide (chemotherapy drug) resistance of glioma. CASC2 is negatively downregulated with miR-193a-5p in temozolomide resistant glioma tissues and induce autophagy by controlling mTOR expression to promote drug resistance (Jiang et al., 2018). Ma et al. (2017b) have described lncRNA AC023115.3 up-regulated in glioma cells after cisplatin treatment and induce cisplatin-mediated apoptosis by inhibiting autophagy process via miR-26a/GSK3 $\beta$ axis. Wang and colleagues showed that lncRNA CTA (CTA) is significantly downregulated in OSTS cells and cancer tissues in contrast with the adjacent normal tissues. CTA downregulated expression is also associated with the advanced TNM stage, larger tumor size and reduced chemosensitivity of doxorubicin through autophagy process (Wang Z. et al., 2017). Micro-RNA miR-210 is negatively regulated with CTA in OSTS and promote apoptosis of OSTS cells, whilst overexpression of 
CTA inhibit autophagy and sensitize to doxorubicin subsequently in both in vitro and in vivo (Wang $Z$. et al., 2017). PCA3 is a newly identified lncRNA, located on chromosome 9q2122 and highly specific for PTC (Popa et al., 2007). He et al. (2016) reported that PCA3 is overexpressed in PTC to promote proliferation, migration, and invasion by sponging miR-1261 through inhibiting PRKD3 and blocking protective autophagy. On the other hand, silencing of PCA3 is able to induce protective autophagy and lessen the PTC progression which could be a novel target of personalized treatment (He et al., 2016). Shan's team established that, silencing of lncRNA POU3F3 significantly reduce CRC cells proliferation, migration, and activate autophagy process by enhancing the expression of autophagy-related genes and proteins Beclin-1, ATG5, ATG7, and LC3 II which is novel therapeutic target of CRC (Shan et al., 2016).

\section{AUTOPHAGY-MODULATING LncRNAs EITHER INDUCE OR INHIBIT AUTOPHAGY IN CANCER}

In the literature, we found some reports describing the same lncRNA but with opposite relationship with autophagy. Here, we include three examples which have been studied extensively.

\section{Highly Up-Regulated in Liver Cancer}

Highly up-regulated in liver cancer was an lncRNA originally characterized in HCC as a significantly overexpressed lncRNA (Panzitt et al., 2007). HULC contains two exons, 1.6k nucleotides in length, located on chromosome 6p24.3. It is significantly dysregulated in most of the cancers including CRC, GC, HCC, OSTS and PNC (Panzitt et al., 2007; Chen et al., 2017c; Li et al., 2017g; Ma et al., 2017d; Shaker et al., 2017; Yu et al., 2017). A number of groups addressed HULC dysregulation and its molecular mechanisms in various cancer cells proliferation, migration, apoptosis, and metastasis but limited reports have focused on autophagy. Zhao et al. (2014) established that overexpression of HULC is clinically correlated with the developmental process of GC by promoted proliferation, migration, invasion, and reduced cellular apoptosis by inducing autophagy. Xiong et al. (2017) found that HULC overexpression induces autophagy and resulting in reduced chemosensitivity of potent chemo drugs 5-fluorouracil, oxaliplatin, and pirarubicin in HCC cells. Moreover, inhibition of protective autophagy by silencing of HULC sensitize these three drugs activity through controlling sirtl protein in HCC (Xiong et al., 2017). In the contrary, Chen et al. (2017a) reported that HULC suppresses in vitro apoptosis and in vivo tumor development through autophagy blockage in epithelial ovarian carcinoma. Up-regulated HULC inhibits expression of ATG7, LC3-II, and LAMP1 while activates SQSTM1/p62 to promote carcinogenic events (Chen et al., 2017a).

\section{Growth Arrest-Specific 5}

LncRNA GAS5 was first identified in 1988. It is a tumor suppressor lncRNA which contains 630 nucleotides and encoded at chromosome 1q25 (Schneider et al., 1988). So far, it is wellestablished that GAS5 plays key roles in diverse molecular functions in cancers (Pickard and Williams, 2015; Ma et al., 2016; Gao Q. et al., 2017). Meta-analysis of GAS5 shown that, it is associated with DFS, OS, LNM and tumor stages (I, II, III, IV) (Gao Q. et al., 2017). GAS5 is well-known for the negative regulation of most cancer cells survival (Song et al., 2014). Zhang and co-workers have demonstrated that down-regulating GAS5 would inhibit autophagy in NSCLC and facilitate drug resistance. Overexpression of GAS5 through vector mediated transfection induced autophagy and promote chemotherapy (cisplatin) response in NSCLC cells (Zhang et al., 2016). Gu et al. (2018) reported that GAS5 expression and autophagy were both downregulated in BRC cells and patients sample GAS5 expression is negatively correlated with depth tumor size, advanced TNM and poor prognosis of diseases. Interestingly, vector-mediated overexpression of GAS5 triggers autophagy and increases LC3, ATG3, and p62 expressions through sponging miR-23a. These findings may be developed into a targeted therapy for BRC through GAS5/miR-23a/ATG3 axis (Gu et al., 2018). However, another experiment conducted by Huo's group also demonstrated reduced GAS5 expression in cisplatin-resistant glioma cell lines. Further investigations on the mechanisms have shown that GAS5 down-regulated glioma cells become resistant to cisplatin by increasing autophagosomes formation (Huo and Chen, 2018).

\section{Regulator of Reprogramming}

The lncRNA ROR was first identified in pluripotent stem cells. It contains four exons, totally $2.6 \mathrm{~kb}$ in length and is located on chromosome 18q21.31 (Loewer et al., 2010; Zhan et al., 2016). ROR has been reported to be involved in isolated cellular processes, including growth, proliferation, migration, apoptosis, autophagy and metastasis of BRC, CRC, GC, HCC, NPC, and PNC cancers (Takahashi et al., 2014; Pan et al., 2016; Wang S. et al., 2016; Zhan et al., 2016; Li et al., 2017a; Peng et al., 2017; Wang Y. et al., 2017). Chen Y.M. et al. (2016) proved that ROR suppress autophagy and gemcitabine-induced cell death (apoptosis) in BRC cells by regulating miR-34a. In another study, however, Li's team showed that ROR is up-regulated in PNC to promote basal autophagy which suppresses PKM2 and reduce chemo-sensitivity (gemcitabine) of cells ( $\mathrm{Li} \mathrm{C}$. et al., 2016). Li et al. (2017f) also identified ROR overexpression reduce autophagy to increase proliferation, invasion, migration, and tamoxifen resistance in BRC cells and tissues. On the other hand, silencing of ROR effectively increases the sensitivity of tamoxifen, proliferation, and migration by inducing autophagy ( $\mathrm{Li}$ et al., 2017f).

\section{DISCUSSION}

Advanced technologies have improved our understanding of the role of lncRNAs in cancer. At this stage, it is hard to consider lncRNAs as cancer biomarker because the sensitivity and specificity are still not at the desired level. However, researchers may consider using the autophagy-modulating lncRNAs for the 
development of biomarkers and targeted cancer therapy. From the growing research based knowledge on lncRNAs, autophagy and cancers, we may declare that most lncRNAs are involved in tumorigenesis through inducing or inhibiting the autophagy pathway.

Autophagy is a conserved regulatory process which is essential for both normal and cancer microenvironments under stress and hypoxic conditions (Xu et al., 2017). Advances in NGS technologies identified more than 3500 putative lncRNAs and the epigenetic roles of lncRNAs have been identified in many diseases including cancers. The discovery of lncRNAs and their molecular signals in cancers through autophagy process has drawn keen attention by scientists as biomarkers and targets for cancer therapy of lncRNAs/autophagy modulated diseases (Xu et al., 2017). However, autophagy and lncRNAs research is still in its fancy compared to its quantity, limited research methods of relationship establishment studies and inadequate therapeutic and clinical trials. Therefore, a major part is still under investigations. The effects of autophagy-modulating lncRNAs are very controversial from its discovery. Both autophagy and lncRNAs may accelerate the carcinogenesis or suppress the cancers (Wang et al., 2015; Liu et al., 2016; Lu et al., 2017; Ma et al., 2017b; Xu et al., 2017). In addition, the dual roles playing autophagy and lncRNAs made of difficult to comprehend the regulatory mechanisms in cancers (Zhang J. et al., 2017).

The regulatory process of autophagy composed of initiation, phagophore nucleation, autophagosome structure formation, and autolysosomal fusion to degrade the unwanted proteins or cytoplasmic components from the body (Mizushima, 2007). It is now well-established that lncRNAs participate in cellular regulatory autophagy pathways (Xu et al., 2017; Yang et al., 2017; Sun, 2018), for example, H19, BRCA1, MEG3, PTENP1, and MALAT1 are involved in initiation; ROR, loc146880, and AC023115.3 are involved in nucleation; TGFB2-OT1, GAS5, HNF1A-AS1, PCGEM1, and HULC are involved in elongation; Chast and MALAT1 are involved in lysosomal fusion process (Yang et al., 2017). With the perspective of ATGs genes, lncRNAs provided a new paradigm of gene expression in the autophagy pathway. An increasing number of lncRNAs have been identified in cancer which triggers autophagy to either promotion or suppression of carcinogenesis (Xu et al., 2017; Sun, 2018). It is now a precious research question that, does autophagy impact on the expression of lncRNAs to promote or suppress cancer? So far, PVT1 is the only reported lncRNA which is regulated by autophagy in diabetes ( $\mathrm{Li} \mathrm{Z}$. et al., 2016). To address this question in cancer we are currently working on autophagy regulated lncRNAs and their impact on CRC pathogenesis.

\section{REFERENCES}

Amaravadi, R., Kimmelman, A. C., and White, E. (2016). Recent insights into the function of autophagy in cancer. Genes Dev. 30, 1913-1930. doi: 10.1101/gad. 287524.116

Avalos, Y., Canales, J., Bravo-Sagua, R., Criollo, A., Lavandero, S., and Quest, A. F. (2014). Tumor suppression and promotion by autophagy. Biomed. Res. Int. 2014:603980. doi: 10.1155/2014/603980

\section{CONCLUSION AND INSIGHTS}

Cancer is the second leading cause of death worldwide. Incidences and deaths are increasing because of poor understanding of the disease, diagnostic techniques, and proper treatments. Progression of treatments remains dissatisfactory because most of the cancer patients were diagnosed after development of metastasis. Recently circulating lncRNAs has been considered for diagnostic and therapeutic purpose even though their mechanisms remain unclear (Qi et al., 2016; Sun, 2017). In this review, we have described the roles autophagyregulated lncRNAs on cancer (Table 1), and their impact on autophagy regulation through the distinct network (Figure 3). At present, the research on the lncRNAs involvement on autophagy pathways is still in its primary stage. Although every day new lncRNAs are reporting on various cancer type, most of the researchs mainly focused on their impact on cancer pathogenesis. By considering the lncRNAs impact on autophagy mechanisms (Yang et al., 2017), more critical functions underlying autophagy are waiting to be demonstrated. Some autophagy-modulated lncRNAs described in this review are very specific with identical tissue types, for example HULC, PCA3, PVT1 may serve as a potential biomarkers and target therapy in identical cancer types (He et al., 2016; Ma et al., 2017c; Xiong et al., 2017). Therefore, extensive studies are needed to address the interaction between lncRNAs and the complex regulatory autophagy process with selective target genes and signaling transductions for the discovery of new targets, prognostic and diagnostic biomarkers and target therapy.

\section{AUTHOR CONTRIBUTIONS}

All authors have participated sufficiently in the work to take public responsibility for the content. We have worked together in the conception, drafting and revising the articles to provide an intellectual content of critical importance to the work described and final approval of the version to be published.

\section{FUNDING}

This work was supported by Departmental Start-up and Seed Funding for HL, and Departmental Postgraduate Funds for MK and ST, The Hong Kong Polytechnic University.

Bao, X., Ren, T., Huang, Y., Sun, K., Wang, S., Liu, K., et al. (2017). Knockdown of long non-coding RNA HOTAIR increases miR-454-3p by targeting Stat3 and Atg12 to inhibit chondrosarcoma growth. Cell Death Dis. 8:e2605. doi: 10.1038/cddis.2017.31

Blessing, A. M., Rajapakshe, K., Reddy Bollu, L., Shi, Y., White, M. A., Pham, A. H., et al. (2017). Transcriptional regulation of core autophagy and lysosomal genes by the androgen receptor promotes prostate cancer progression. Autophagy 13, 506-521. doi: 10.1080/15548627.2016.1268300 
Bogenrieder, T., and Herlyn, M. (2003). Axis of evil: molecular mechanisms of cancer metastasis. Oncogene 22, 6524-6536. doi: 10.1038/sj.onc. 1206757

Brannan, C. I., Dees, E. C., Ingram, R. S., and Tilghman, S. M. (1990). The product of the H19 gene may function as an RNA. Mol. Cell Biol. 10, 28-36. doi: $10.1128 / \mathrm{MCB} \cdot 10.1 .28$

Chen, C. L., Tseng, Y. W., Wu, J. C., Chen, G. Y., Lin, K. C., Hwang, S. M., et al. (2015). Suppression of hepatocellular carcinoma by baculovirus-mediated expression of long non-coding RNA PTENP1 and MicroRNA regulation. Biomaterials 44, 71-81. doi: 10.1016/j.biomaterials.2014.12.023

Chen, S., Wu, D.-D., Sang, X.-B., Wang, L.-L., Zong, Z.-H., Sun, K.-X., et al. (2017a). The lncRNA HULC functions as an oncogene by targeting ATG7 and ITGB1 in epithelial ovarian carcinoma. Cell Death Dis. 8:e3118. doi: 10.1038/ cddis. 2017.486

Chen, S., Zhu, J., Wang, F., Guan, Z., Ge, Y., Yang, X., et al. (2017b). LncRNAs and their role in cancer stem cells. Oncotarget 8, 110685-110692. doi: 10.18632/ oncotarget.22161

Chen, T., Yang, P., and He, Z. Y. (2016). Long non-coding RNA H19 can predict a poor prognosis and lymph node metastasis: a meta-analysis in human cancer. Minerva Med. 107, 251-258.

Chen, X., Lun, L., Hou, H., Tian, R., Zhang, H., and Zhang, Y. (2017c). The value of IncRNA HULC as a prognostic factor for survival of cancer outcome: a meta-analysis. Cell. Physiol. Biochem. 41, 1424-1434. doi: 10.1159/000468005

Chen, Y.-M., Liu, Y., Wei, H.-Y., Lv, K.-Z., and Fu, P.-F. (2016). Large intergenic non-coding RNA-ROR reverses gemcitabine-induced autophagy and apoptosis in breast cancer cells. Oncotarget 7, 59604-59617. doi: 10.18632/oncotarget. 10730

Cicchini, M., Karantza, V., and Xia, B. (2015). Molecular pathways: autophagy in cancer-a matter of timing and context. Clin. Cancer Res. 21, 498-504. doi: 10.1158/1078-0432.CCR-13-2438

Cui, H., Onyango, P., Brandenburg, S., Wu, Y., Hsieh, C. L., and Feinberg, A. P. (2002). Loss of imprinting in colorectal cancer linked to hypomethylation of H19 and IGF2. Cancer Res. 62, 6442-6446.

Cui, M., You, L., Ren, X., Zhao, W., Liao, Q., and Zhao, Y. (2016). Long noncoding RNA PVT1 and cancer. Biochem. Biophys. Res. Commun. 471, 10-14. doi: 10.1016/j.bbrc.2015.12.101

Ferlay, J., Soerjomataram, I., Dikshit, R., Eser, S., Mathers, C., Rebelo, M., et al. (2015). Cancer incidence and mortality worldwide: sources, methods and major patterns in GLOBOCAN 2012. Int. J. Cancer 136, E359-E386. doi: 10.1002/ijc. 29210

Fu, Z., Luo, W., Wang, J., Peng, T., Sun, G., Shi, J., et al. (2017). Malat1 activates autophagy and promotes cell proliferation by sponging miR-101 and upregulating STMN1, RAB5A and ATG4D expression in glioma. Biochem. Biophys. Res. Commun. 492, 480-486. doi: 10.1016/j.bbrc.2017.08.070

Gao, D., Lv, A. E., Li, H. P., Han, D. H., and Zhang, Y. P. (2017). LncRNA MALAT-1 Elevates HMGB1 to promote autophagy resulting in inhibition of tumor cell apoptosis in multiple myeloma. J. Cell Biochem. 118, 3341-3348. doi: $10.1002 / j \mathrm{cb} .25987$

Gao, Q., Xie, H., Zhan, H., Li, J., Liu, Y., and Huang, W. (2017). Prognostic values of long noncoding RNA GAS5 in various carcinomas: an updated systematic review and meta-analysis. Front. Physiol. 8:814. doi: 10.3389/fphys.2017.00814

GBD 2015 Risk Factors Collaborators (2016). Global, regional, and national comparative risk assessment of 79 behavioural, environmental and occupational, and metabolic risks or clusters of risks, 1990-2015: a systematic analysis for the Global Burden of Disease Study 2015. Lancet 388, 1659-1724. doi: 10.1016/S0140-6736(16)31679-8

Gerardo, B., Laura, M., Maria Gabriella, M., Annamaria, A., Chiara, B., Renato, F., et al. (2017). LncRNA HOTAIR as prognostic circulating marker and potential therapeutic target in patients with tumor diseases. Curr. Drug Targets 18, 27-34.

Gong, X., and Huang, M. (2017). Long non-coding RNA MEG3 promotes the proliferation of glioma cells through targeting Wnt/beta-catenin signal pathway. Cancer Gene Ther. 24, 381-385. doi: 10.1038/cgt.2017.32

Gu, J., Wang, Y., Wang, X., Zhou, D., Wang, X., Zhou, M., et al. (2018). Effect of the LncRNA GAS5-MiR-23a-ATG3 axis in regulating autophagy in patients with breast cancer. Cell. Physiol. Biochem. 48, 194-207. doi: 10.1159/000491718

Guo, D., Wang, Y., Ren, K., and Han, X. (2018). Knockdown of LncRNA PVT1 inhibits tumorigenesis in non-small-cell lung cancer by regulating miR-497 expression. Exp. Cell Res. 362, 172-179. doi: 10.1016/j.yexcr.2017.11.014
Gutschner, T., Hämmerle, M., and Diederichs, S. (2013). MALAT1 - a paradigm for long noncoding RNA function in cancer. J. Mol. Med. 91, 791-801. doi: 10.1007/s00109-013-1028-y

He, J. H., Li, B. X., Han, Z. P., Zou, M. X., Wang, L., Lv, Y. B., et al. (2016). Snail-activated long non-coding RNA PCA3 up-regulates PRKD3 expression by miR-1261 sponging, thereby promotes invasion and migration of prostate cancer cells. Tumour Biol. doi: 10.1007/s13277-016-5450-y [Epub ahead of print].

He, Y., Luo, Y., Liang, B., Ye, L., Lu, G., and He, W. (2017). Potential applications of MEG3 in cancer diagnosis and prognosis. Oncotarget 8, 73282-73295. doi: 10.18632/oncotarget.19931

Hou, Z., Xu, X., Zhou, L., Fu, X., Tao, S., Zhou, J., et al. (2017). The long non-coding RNA MALAT1 promotes the migration and invasion of hepatocellular carcinoma by sponging miR-204 and releasing SIRT1. Tumour Biol. 39:1010428317718135. doi: 10.1177/1010428317718135

Hu, M.-C., He, J.-Y., Hu, Y.-H., Hong, J.-W., and Zhang, J. (2016). Long noncoding RNA $\mathrm{H} 19$ as a prognostic marker in human cancer: a meta-analysis. Int. J. Clin. Exp. Pathol. 9, 5015-5024.

Hu, X., Sood, A. K., Dang, C. V., and Zhang, L. (2018). The role of long noncoding RNAs in cancer: the dark matter matters. Curr. Opin. Genet. Dev. 48, 8-15. doi: 10.1016/j.gde.2017.10.004

Huang, F., Chen, W., Peng, J., Li, Y., Zhuang, Y., Zhu, Z., et al. (2018). LncRNA PVT1 triggers Cyto-protective autophagy and promotes pancreatic ductal adenocarcinoma development via the miR-20a-5p/ULK1 Axis. Mol. Cancer 17:98. doi: 10.1186/s12943-018-0845-6

Huang, J., Yang, Y., Fang, F., and Liu, K. (2017). MALAT1 modulates the autophagy of retinoblastoma cell through miR-124-mediated stx17 regulation. J. Cell Biochem. 119, 3853-3863. doi: 10.1002/jcb.26464

Huang, X., Xiao, R., Pan, S., Yang, X., Yuan, W., Tu, Z., et al. (2017). Uncovering the roles of long non-coding RNAs in cancer stem cells. J. Hematol. Oncol. 10:62. doi: 10.1186/s13045-017-0428-9

Huo, J. F., and Chen, X. B. (2018). Long noncoding RNA growth arrest-specific 5 facilitates glioma cell sensitivity to cisplatin by suppressing excessive autophagy in an mTOR-dependent manner. J. Cell Biochem. doi: 10.1002/jcb.27900 [Epub ahead of print].

Işın, M., Uysaler, E., Özgür, E., Köseoğlu, H., Şanl, Ö., Yücel, Ö. B., et al. (2015). Exosomal lncRNA-p21 levels may help to distinguish prostate cancer from benign disease. Front. Genet. 6:168. doi: 10.3389/fgene.2015.00168

Ji, P., Diederichs, S., Wang, W., Böing, S., Metzger, R., Schneider, P. M., et al. (2003). MALAT-1, a novel noncoding RNA, and thymosin $\beta 4$ predict metastasis and survival in early-stage non-small cell lung cancer. Oncogene 22, 8031-8041. doi: 10.1038/sj.onc. 1206928

Jiang, C., Shen, F., Du, J., Fang, X., Li, X., Su, J., et al. (2018). Upregulation of CASC2 sensitized glioma to temozolomide cytotoxicity through autophagy inhibition by sponging miR-193a-5p and regulating mTOR expression. Biomed. Pharmacother. 97, 844-850. doi: 10.1016/j.biopha.2017. 10.146

Kim, K. H., and Lee, M.-S. (2014). Autophagy-a key player in cellular and body metabolism. Nat. Rev. Endocrinol. 10, 322-337. doi: 10.1038/nrendo. 2014.35

Ktistakis, N. T., and Tooze, S. A. (2016). Digesting the expanding mechanisms of autophagy. Trends Cell Biol. 26, 624-635. doi: 10.1016/j.tcb.2016.03.006

Kung, C. P., Budina, A., Balaburski, G., Bergenstock, M. K., and Murphy, M. (2011). Autophagy in tumor suppression and cancer therapy. Crit. Rev. Eukaryot. Gene Expr. 21, 71-100. doi: 10.1615/CritRevEukarGeneExpr. v21.i1.50

Li, C., Zhao, Z., Zhou, Z., and Liu, R. (2016). Linc-ROR confers gemcitabine resistance to pancreatic cancer cells via inducing autophagy and modulating the miR-124/PTBP1/PKM2 axis. Cancer Chemother. Pharmacol. 78, 1199-1207. doi: 10.1007/s00280-016-3178-4

Li, H., Chen, S., Liu, J., Guo, X., Xiang, X., Dong, T., et al. (2018). Long non-coding RNA PVT1-5 promotes cell proliferation by regulating miR-126/SLC7A5 axis in lung cancer. Biochem. Biophys. Res. Commun. 495, 2350-2355. doi: 10.1016/ j.bbrc.2017.12.114

Li, H., Jiang, X., and Niu, X. (2017a). Long non-coding RNA Reprogramming (ROR) promotes cell proliferation in colorectal cancer via affecting P53. Med. Sci. Monit. 23, 919-928. 
Li, J., Yang, C., Li, Y., Chen, A., Li, L., and You, Z. (2017b). LncRNA GAS5 suppresses ovarian cancer by inducing inflammasome formation. Biosci. Rep. 38: BSR20171150. doi: 10.1042/BSR20171150

Li, L., Chen, H., Gao, Y., Wang, Y.-W., Zhang, G.-Q., Pan, S.-H., et al. (2016). Long noncoding RNA MALAT1 promotes aggressive pancreatic cancer proliferation and metastasis via the stimulation of autophagy. Mol. Cancer Ther. 15, 22322243. doi: 10.1158/1535-7163.MCT-16-0008

Li, M., Chai, H.-F., Peng, F., Meng, Y.-T., Zhang, L.-Z., Zhang, L., et al. (2018). Estrogen receptor $\beta$ upregulated by lncRNA-H19 to promote cancer stemlike properties in papillary thyroid carcinoma. Cell Death Dis. 9, 1120-1120. doi: 10.1038/s41419-018-1077-9

Li, S., Mei, Z., and Hu, H. B. (2017c). The lncRNA MALAT1 contributes to nonsmall cell lung cancer development via modulating miR-124/STAT3 axis. J. Cell. Physiol. 233, 6679-6688. doi: 10.1002/jcp.26325

Li, X., Chen, W., Wang, H., Wei, Q., Ding, X., and Li, W. (2017d). Amplification and the clinical significance of circulating cell-free DNA of PVT1 in breast cancer. Oncol. Rep. 38, 465-471. doi: 10.3892/or.2017.5650

Li, Y., Gu, J., and Lu, H. (2017e). The GAS5/miR-222 axis regulates proliferation of gastric cancer cells through the PTEN/Akt/mTOR pathway. Dig. Dis. Sci. 62, 3426-3437. doi: 10.1007/s10620-017-4831-4

Li, Y., Jiang, B., Zhu, H., Qu, X., Zhao, L., Tan, Y., et al. (2017f). Inhibition of long non-coding RNA ROR reverses resistance to Tamoxifen by inducing autophagy in breast cancer. Tumour Biol. 39:1010428317705790. doi: 10.1177/ 1010428317705790

Li, Z., Dou, P., Liu, T., and He, S. (2017g). Application of long noncoding RNAs in osteosarcoma: biomarkers and therapeutic targets. Cell. Physiol. Biochem. 42, 1407-1419. doi: 10.1159/000479205

Li, Z., Hao, S., Yin, H., Gao, J., and Yang, Z. (2016). Autophagy ameliorates cognitive impairment through activation of PVT1 and apoptosis in diabetes mice. Behav. Brain Res. 305, 265-277. doi: 10.1016/j.bbr.2016. 03.023

Lin, C.-P., and He, L. (2017). Noncoding RNAs in cancer development. Annu. Rev. Cancer Biol. 1, 163-184. doi: 10.1146/annurev-cancerbio-050216-034443

Liu, Z., Wei, X., Zhang, A., Li, C., Bai, J., and Dong, J. (2016). Long non-coding RNA HNF1A-AS1 functioned as an oncogene and autophagy promoter in hepatocellular carcinoma through sponging hsa-miR-30b-5p. Biochem. Biophys. Res. Commun. 473, 1268-1275. doi: 10.1016/j.bbrc.2016.04.054

Loewen, G., Jayawickramarajah, J., Zhuo, Y., and Shan, B. (2014). Functions of lncRNA HOTAIR in lung cancer. J. Hematol. Oncol. 7:90. doi: 10.1186/s13045014-0090-4

Loewer, S., Cabili, M. N., Guttman, M., Loh, Y. H., Thomas, K., Park, I. H., et al. (2010). Large intergenic non-coding RNA-RoR modulates reprogramming of human induced pluripotent stem cells. Nat. Genet. 42, 1113-1117. doi: 10.1038/ ng.710

Lu, D., Luo, P., Wang, Q., Ye, Y., and Wang, B. (2017). lncRNA PVT1 in cancer: a review and meta-analysis. Clin. Chim. Acta 474, 1-7. doi: 10.1016/j.cca.2017. 08.038

Luo, J., Qu, J., Wu, D.-K., Lu, Z.-L., Sun, Y.-S., and Qu, Q. (2017). Long non-coding RNAs: a rising biotarget in colorectal cancer. Oncotarget 8, 22187-22202. doi: 10.18632/oncotarget.14728

Ma, B., Gao, Z., Lou, J., Zhang, H., Yuan, Z., Wu, Q., et al. (2017a). Long noncoding RNA MEG3 contributes to cisplatininduced apoptosis via inhibition of autophagy in human glioma cells. Mol. Med. Rep. 16, 2946-2952. doi: 10. 3892/mmr.2017.6897

Ma, B., Yuan, Z., Zhang, L., Lv, P., Yang, T., Gao, J., et al. (2017b). Long non-coding RNA AC023115.3 suppresses chemoresistance of glioblastoma by reducing autophagy. Biochim. Biophys. Acta 1864, 1393-1404. doi: 10.1016/j.bbamcr. 2017.05.008

Ma, Y., Wang, P., Xue, Y., Qu, C., Zheng, J., Liu, X., et al. (2017c). PVT1 affects growth of glioma microvascular endothelial cells by negatively regulating miR-186. Tumour Biol. 39:1010428317694326. doi: 10.1177/1010428317694326

Ma, Z., Huang, H., Xu, Y., He, X., Wang, J., Hui, B., et al. (2017d). Current advances of long non-coding RNA highly upregulated in liver cancer in human tumors. Onco Targets Ther. 10, 4711-4717. doi: 10.2147/OTT.S136915

Ma, C., Shi, X., Zhu, Q., Li, Q., Liu, Y., Yao, Y., et al. (2016). The growth arrest-specific transcript 5 (GAS5): a pivotal tumor suppressor long noncoding RNA in human cancers. Tumor Biol. 37, 1437-1444. doi: 10.1007/s13277-015$4521-9$
Ma, L., Wang, F., Du, C., Zhang, Z., Guo, H., Xie, X., et al. (2018). Long non-coding RNA MEG3 functions as a tumour suppressor and has prognostic predictive value in human pancreatic cancer. Oncol. Rep. 39, 1132-1140. doi: 10.3892/or. 2018.6178

Matouk, I. J., Halle, D., Raveh, E., Gilon, M., Sorin, V., and Hochberg, A. (2016). The role of the oncofetal H19 lncRNA in tumor metastasis: orchestrating the EMT-MET decision. Oncotarget 7, 3748-3765. doi: 10.18632/oncotarget.6387

Miao, Z., Ding, J., Chen, B., Yang, Y., and Chen, Y. (2016). HOTAIR overexpression correlated with worse survival in patients with solid tumors. Minerva Med. 107, 392-400.

Miyoshi, N., Wagatsuma, H., Wakana, S., Shiroishi, T., Nomura, M., Aisaka, K., et al. (2000). Identification of an imprinted gene, Meg3/Gtl2 and its human homologue MEG3, first mapped on mouse distal chromosome 12 and human chromosome 14q. Genes Cells 5, 211-220. doi: 10.1046/j.1365-2443.2000. 00320.x

Mizushima, N. (2007). Autophagy: process and function. Genes Dev. 21, 28612873. doi: $10.1101 /$ gad.1599207

Mizushima, N., and Komatsu, M. (2011). Autophagy: renovation of cells and tissues. Cell 147, 728-741. doi: 10.1016/j.cell.2011.10.026

Mowers, E. E., Sharifi, M. N., and Macleod, K. F. (2016). Autophagy in cancer metastasis. Oncogene 36, 1619-1630. doi: 10.1038/onc.2016.333

Mowers, E. E., Sharifi, M. N., and Macleod, K. F. (2017). Autophagy in cancer metastasis. Oncogene 36, 1619-1630. doi: 10.1038/onc.2016.333

Pan, Y., Li, C., Chen, J., Zhang, K., Chu, X., Wang, R., et al. (2016). The Emerging roles of long noncoding RNA ROR (lincRNA-ROR) and its possible mechanisms in human cancers. Cell. Physiol. Biochem. 40, 219-229. doi: 10. $1159 / 000452539$

Panzitt, K., Tschernatsch, M. M., Guelly, C., Moustafa, T., Stradner, M., Strohmaier, H. M., et al. (2007). Characterization of HULC, a novel gene with striking upregulation in hepatocellular carcinoma, as noncoding RNA. Gastroenterology 132, 330-342. doi: 10.1053/j.gastro.2006.08.026

Peng, W. X., Huang, J. G., Yang, L., Gong, A. H., and Mo, Y. Y. (2017). Linc-RoR promotes MAPK/ERK signaling and confers estrogen-independent growth of breast cancer. Mol. Cancer 16:161. doi: 10.1186/s12943-017-0727-3

Pickard, M. R., and Williams, G. T. (2015). Molecular and cellular mechanisms of action of tumour suppressor GAS5 LncRNA. Genes 6, 484-499. doi: 10.3390/ genes6030484

Popa, I., Fradet, Y., Beaudry, G., Hovington, H., Beaudry, G., and Têtu, B. (2007). Identification of PCA3 (DD3) in prostatic carcinoma by in situ hybridization. Mod. Pathol. 20, 1121-1127. doi: 10.1038/modpathol.3800963

Qi, P., Zhou, X. Y., and Du, X. (2016). Circulating long non-coding RNAs in cancer: current status and future perspectives. Mol. Cancer 15:39. doi: 10.1186/s12943016-0524-4

Rinn, J. L., Kertesz, M., Wang, J. K., Squazzo, S. L., Xu, X., Brugmann, S. A., et al. (2007). Functional demarcation of active and silent chromatin domains in human HOX loci by noncoding RNAs. Cell 129, 1311-1323. doi: 10.1016/j. cell.2007.05.022

Sankaranarayanan, R., Ramadas, K., and Qiao, Y.-L. (2014). Managing the changing burden of cancer in Asia. BMC Med. 12:3. doi: 10.1186/17417015-12-3

Santana-Codina, N., Mancias, J. D., and Kimmelman, A. C. (2017). The role of autophagy in cancer. Annu. Rev. Cancer Biol. 1, 19-39. doi: 10.1146/annurevcancerbio-041816-122338

Schneider, C., King, R. M., and Philipson, L. (1988). Genes specifically expressed at growth arrest of mammalian cells. Cell 54, 787-793. doi: 10.1016/S00928674(88)91065-3

Shaker, O. G., Senousy, M. A., and Elbaz, E. M. (2017). Association of rs6983267 at $8 \mathrm{q} 24$, HULC rs7763881 polymorphisms and serum lncRNAs CCAT2 and HULC with colorectal cancer in Egyptian patients. Sci. Rep. 7:16246. doi: 10. 1038/s41598-017-16500-4

Shan, T. D., Xu, J. H., Yu, T., Li, J. Y., Zhao, L. N., Ouyang, H., et al. (2016). Knockdown of linc-POU3F3 suppresses the proliferation, apoptosis, and migration resistance of colorectal cancer. Oncotarget 7, 961-975. doi: 10. 18632/oncotarget.5830

Shen, Y., Liu, Y., Sun, T., and Yang, W. (2017). LincRNA-p21 knockdown enhances radiosensitivity of hypoxic tumor cells by reducing autophagy through HIF1/Akt/mTOR/P70S6K pathway. Exp. Cell Res. 358, 188-198. doi: 10.1016/j. yexcr.2017.06.016 
Song, J., Ahn, C., Chun, C.-H., and Jin, E.-J. (2014). A long non-coding RNA, GAS5, plays a critical role in the regulation of miR-21 during osteoarthritis. J. Orthop. Res. 32, 1628-1635. doi: 10.1002/jor.22718

Sun, M. Y., Zhu, J. Y., Zhang, C. Y., Zhang, M., Song, Y. N., Rahman, K., et al. (2017). Autophagy regulated by lncRNA HOTAIR contributes to the cisplatininduced resistance in endometrial cancer cells. Biotechnol. Lett. 39, 1477-1484. doi: 10.1007/s10529-017-2392-4

Sun, T. (2017). Long noncoding RNAs act as regulators of autophagy in cancer. Pharmacol. Res. 129, 151-155. doi: 10.1016/j.phrs.2017.11.009

Sun, T. (2018). Long noncoding RNAs act as regulators of autophagy in cancer. Pharmacol Res 129, 151-155. doi: 10.1016/j.phrs.2017.11.009

Takahashi, K., Yan, I. K., Kogure, T., Haga, H., and Patel, T. (2014). Extracellular vesicle-mediated transfer of long non-coding RNA ROR modulates chemosensitivity in human hepatocellular cancer. FEBS Open Biol 4, 458-467. doi: 10.1016/j.fob.2014.04.007

Wang, K., Liu, C. Y., Zhou, L. Y., Wang, J. X., Wang, M., Zhao, B., et al. (2015). APF lncRNA regulates autophagy and myocardial infarction by targeting miR188-3p. Nat. Commun. 6:6779. doi: 10.1038/ncomms7779

Wang, P., Chen, D., Ma, H., and Li, Y. (2017). LncRNA MEG3 enhances cisplatin sensitivity in non-small cell lung cancer by regulating miR-21-5p/SOX7 axis. Onco Targets Ther. 10, 5137-5149. doi: 10.2147/OTT.S146423

Wang, S., Liu, F., Deng, J., Cai, X., Han, J., and Liu, Q. (2016). Long noncoding RNA ROR regulates proliferation, invasion, and stemness of gastric cancer stem cell. Cell Reprogram. 18, 319-326. doi: 10.1089/cell.2016.0001

Wang, Y., Guo, Z., Zhao, Y., Jin, Y., An, L., Wu, B., et al. (2017). Genetic polymorphisms of lncRNA-p53 regulatory network genes are associated with concurrent chemoradiotherapy toxicities and efficacy in nasopharyngeal carcinoma patients. Sci. Rep. 7:8320. doi: 10.1038/s41598-01708890-2

Wang, Z., Liu, Z., and Wu, S. (2017). Long non-coding RNA CTA sensitizes osteosarcoma cells to doxorubicin through inhibition of autophagy. Oncotarget 8, 31465-31477. doi: 10.18632/oncotarget.16356

Wang, Z., Yang, H., Wang, X., Wang, L., Cheng, Y., Zhang, Y., et al. (2016). The molecular mechanism and regulatory pathways of cancer stem cells. Cancer Transl. Med. 2, 147-153. doi: 10.4103/2395-3977.192932

Wang, Y., Guo, Q., Zhao, Y., Chen, J., Wang, S., Hu, J., et al. (2014). BRAF-activated long non-coding RNA contributes to cell proliferation and activates autophagy in papillary thyroid carcinoma. Oncol. Lett. 8, 1947-1952. doi: 10.3892/ol.2014. 2487

Wei, G. H., and Wang, X. (2017). IncRNA MEG3 inhibit proliferation and metastasis of gastric cancer via p53 signaling pathway. Eur. Rev. Med. Pharmacol. Sci. 21, 3850-3856.

White, E. (2015). The role for autophagy in cancer. J. Clin. Invest. 125, 42-46. doi: 10.1172/JCI73941

WHO (2018). Cancer (Fact Sheet) [Online]. World Health Organization. Available: http://www.who.int/mediacentre/factsheets/fs297/en/ [accessed Feb 26, 2018]

Xiong, H., Ni, Z., He, J., Jiang, S., Li, X., He, J., et al. (2017). LncRNA HULC triggers autophagy via stabilizing Sirt1 and attenuates the chemosensitivity of HCC cells. Oncogene 36, 3528-3540. doi: 10.1038/onc.2016.521

Xiong, Y., Wang, J., Zhu, H., Liu, L., and Jiang, Y. (2018). Chronic oxymatrine treatment induces resistance and epithelialmesenchymal transition through targeting the long non-coding RNA MALAT1 in colorectal cancer cells. Oncol. Rep. 39, 967-976. doi: 10.3892/or.2018.6204

Xiu, Y. L., Sun, K. X., Chen, X., Chen, S., Zhao, Y., Guo, Q. G., et al. (2017). Upregulation of the lncRNA Meg3 induces autophagy to inhibit tumorigenesis and progression of epithelial ovarian carcinoma by regulating activity of ATG3. Oncotarget 8, 31714-31725. doi: 10.18632/oncotarget.15955

$\mathrm{Xu}$, Z., Yan, Y., Qian, L., and Gong, Z. (2017). Long non-coding RNAs act as regulators of cell autophagy in diseases (Review). Oncol. Rep. 37, 1359-1366. doi: 10.3892/or.2017.5416

Yang, L., Wang, H., Shen, Q., Feng, L., and Jin, H. (2017). Long non-coding RNAs involved in autophagy regulation. Cell Death Dis. 8:e3073. doi: 10.1038/cddis. 2017.464

Yang, L., Zhang, X., Li, H., and Liu, J. (2016). The long noncoding RNA HOTAIR activates autophagy by upregulating ATG3 and ATG7 in hepatocellular carcinoma. Mol. BioSyst. 12, 2605-2612. doi: 10.1039/c6mb00114a
Ying, L., Huang, Y., Chen, H., Wang, Y., Xia, L., Chen, Y., et al. (2013). Downregulated MEG3 activates autophagy and increases cell proliferation in bladder cancer. Mol. Biosyst. 9, 407-411. doi: 10.1039/c2mb25386k

YiRen, H., Yingcong, Y., Sunwu, Y., Keqin, L., Xiaochun, T., Senrui, C., et al. (2017). Long noncoding RNA MALAT1 regulates autophagy associated chemoresistance via miR-23b-3p sequestration in gastric cancer. Mol. Cancer 16:174. doi: 10.1186/s12943-017-0743-3

Yu, X., Ye, X., Lin, H., Feng, N., Gao, S., Zhang, X., et al. (2018). Knockdown of long non-coding RNA LCPAT1 inhibits autophagy in lung cancer. Cancer Biol. Med. 15, 228-237. doi: 10.20892/j.issn.2095-3941.2017. 0150

Yu, X., Zheng, H., Chan, M. T. V., and Wu, W. K. K. (2017). HULC: an oncogenic long non-coding RNA in human cancer. J. Cell. Mol. Med. 21, 410-417. doi: 10.1111/jcmm.12956

Yuan, P., Cao, W., Zang, Q., Li, G., Guo, X., and Fan, J. (2016). The HIF-2alphaMALAT1-miR-216b axis regulates multi-drug resistance of hepatocellular carcinoma cells via modulating autophagy. Biochem. Biophys. Res. Commun. 478, 1067-1073. doi: 10.1016/j.bbrc.2016.08.065

Zeidler, R., Lipp, M., Joos, S., Delecluse, H.-J., Bornkamm, G. W., Klobeck, G., et al. (1994). Breakpoints of burkitt's lymphoma $t(8 ; 22)$ translocations map within a distance of $300 \mathrm{~kb}$ downstream of MYC. Genes Chromosomes Cancer 9, 282-287. doi: 10.1002/gcc.2870090408

Zhan, H. X., Wang, Y., Li, C., Xu, J. W., Zhou, B., Zhu, J. K., et al. (2016). LincRNAROR promotes invasion, metastasis and tumor growth in pancreatic cancer through activating ZEB1 pathway. Cancer Lett. 374, 261-271. doi: 10.1016/j. canlet.2016.02.018

Zhang, C. Y., Yu, M. S., Li, X., Zhang, Z., Han, C. R., and Yan, B. (2017). Overexpression of long non-coding RNA MEG3 suppresses breast cancer cell proliferation, invasion, and angiogenesis through AKT pathway. Tumour Biol. 39: 1010428317701311. doi: 10.1177/1010428317701311

Zhang, J., Wang, P., Wan, L., Xu, S., and Pang, D. (2017). The emergence of noncoding RNAs as Heracles in autophagy. Autophagy 13, 1004-1024. doi: 10.1080/15548627.2017.1312041

Zhang, N., Yang, G. Q., Shao, X. M., and Wei, L. (2016). GAS5 modulated autophagy is a mechanism modulating cisplatin sensitivity in NSCLC cells. Eur. Rev. Med. Pharmacol. Sci. 20, 2271-2277.

Zhang, X. W., Liu, L., Zhang, X. Z., and Bo, P. (2017). Kanglaite inhibits the expression of drug resistance genes through suppressing PVT1 in cisplatinresistant gastric cancer cells. Exp. Ther. Med. 14, 1789-1794. doi: 10.3892/etm. 2017.4650

Zhao, Y., Guo, Q., Chen, J., Hu, J., Wang, S., and Sun, Y. (2014). Role of long non-coding RNA HULC in cell proliferation, apoptosis and tumor metastasis of gastric cancer: a clinical and in vitro investigation. Oncol. Rep. 31, 358-364. doi: 10.3892/or.2013.2850

Zhou, D.-D., Liu, X.-F., Lu, C.-W., Pant, O. P., and Liu, X.-D. (2017). Long non-coding RNA PVT1: Emerging biomarker in digestive system cancer. Cell Proliferation 50:e12398. doi: 10.1111/cpr.12398

Zhou, X., Chen, J., and Tang, W. (2014). The molecular mechanism of HOTAIR in tumorigenesis, metastasis, and drug resistance. Acta Biochim. Biophys. Sin. 46, 1011-1015. doi: 10.1093/abbs/gmu104

Zuo, Y., Li, Y., Zhou, Z., Ma, M., and Fu, K. (2017). Long non-coding RNA MALAT1 promotes proliferation and invasion via targeting miR-129-5p in triple-negative breast cancer. Biomed. Pharmacother. 95, 922-928. doi: 10.1016/ j.biopha.2017.09.005

Conflict of Interest Statement: The authors declare that the research was conducted in the absence of any commercial or financial relationships that could be construed as a potential conflict of interest.

Copyright (c) 2019 Islam Khan, Tam and Law. This is an open-access article distributed under the terms of the Creative Commons Attribution License (CC BY). The use, distribution or reproduction in other forums is permitted, provided the original author(s) and the copyright owner(s) are credited and that the original publication in this journal is cited, in accordance with accepted academic practice. No use, distribution or reproduction is permitted which does not comply with these terms. 